\title{
COMPARISON OF MCDM METHODS FOR INTERCROP SELECTION IN RUBBER PLANTATIONS
}

\author{
Chutiphon Srisawat \& Janjira Payakpate \\ Naresuan University, Thailand \\ ole13th@nu.in.th; janjirap@nu.ac.th
}

\begin{abstract}
This paper describes research undertaken on the use of multicriteria decision making (MCDM) techniques for decision making in the agricultural sector, specifically in rubber plantations. Data about land quality, nutrient levels, intercropping plantings and crop rotation can be analyzed to enable effective decision-making for the sustainable development of agricultural land. One primary factor in the achievement of high crop production levels is the abundance of nutrients in the soil. By evaluating the fertility of the soil, and analyzing the level and constituents of soil nutrients, the suitability of the land for the needs of particular plants can be determined. Crop rotations, and particularly intercropping practices and plant types, can be effectively planned to balance soil nutrient use. Wrong or poor choices in these practices can significantly affect the main crop, with the associated negative economic consequences. The objective of this research was to compare the use of three multi-criteria decision making methods for their effectiveness in providing decision criteria for choosing intercrop plants among rubber trees in plantations. The three methods include (1) the analytic hierarchy process (AHP), (2) the technique for order preference by similarity to ideal solution (TOPSIS), and (3) simple additive weighting (SAW). The AHP method was shown to be the most appropriate decision making approach for this purpose.
\end{abstract}

Keywords: Analytic hierarchy process, intercrop plant, multi criteria decision making.

\section{INTRODUCTION}

Multi Criteria Decision Making (MCDM) models have been applied in many industries and organizations over an extended period of time. The 
development of MCDM modelling as a discipline is closely related to advances in computer technology. There have been many methods available for solving MCDM problems as reviewed by Hwang and Yoon (1981), though some of the methods were criticized as being ad hoc and others considered to be, to a certain degree, unjustified on theoretical or empirical grounds, as suggested by Stewart (1992). However, in general, MCDM methods have been shown to be highly effective in supporting decision making in many areas. The current research investigated the application of MCDM methods to the agricultural industry, particularly in regard to the cultivation of rubber trees. The application of MCDM to the agricultural sector has not been well researched in the past, yet should be applicable in this area for supporting decision making. Different MCDM methods have been compared mostly on the basis of resolve methods, resolve algorithm, and weighted methods.

While intercropping as an agricultural practice is well understood, there is usually no objective data available to individual farmers to ensure the optimal outcomes of intercropping practices. It has long been a practice to grow intercrops of such products as pineapples, sweet corn, shallots, papaya etc., and to grow two or more crops of these various plants simultaneously and mixed together in the same field. This has been done to improve the use of available resources, and to increase yield and its stability compared to sole cropping (Willey, 1979; Ofori \& Stern, 1978 ; Miao et al., 2016). Nevertheless performance has usually been very variable and depends on environmental conditions, crop management and the level of competition between crop species (Corre-Hellou, Fustec, \& Crozat, 2006). In intercropping systems, crop species compete for several resources such as light, water and nutrients. The interaction of these growth factors in respect to plant or crop growth and resource usage in intercropping systems is highly complex. As well, species interactions may vary over time. By taking into account the complexity of species interactions, modelling can be a very useful tool to study such systems and to test new strategies in various soil and climatic conditions. The advantage of intercrops is that the primary species and the intercropping species do not compete for exactly the same resource niche and thereby tend to use resources in a complementary way (Hauggaard-Nielsen, Ambus, \& Jensen, 2001a; Hauggaard-Nielsen, Ambus, \& Jensen, 2001b; Snaydon \& Satorre, 1989; Hamzei \& Seyyedi, 2016; Hu et al., 2016). The key advantages of intercropping include increased production, more beneficial use of environmental resources, reduction of pests, diseases and weed damage, stability and uniformity of yield, and improved soil fertility and increased nitrogen.

In this paper, three MCDM methods (analytic hierarchy process - AHP, technique for order preference by similarity to ideal solution - TOPSIS, and simple additive weighting - SAW) are examined. The benefits and limitations 
of each method are identified to assist decision makers in choosing the most appropriate MCDM technique for intercrop selection in rubber plantations. The following sections outline the overview of multi criteria decision making and its examples in agriculture sector, three methods of MCDM (as mention previously), a framework of intercrop selection in rubber plantations, comparing three MCDM methods on the previous framework and conclusion.

\section{MULTI CRITERIA DECISION MAKING}

Multi Criteria Decision Making (MCDM) is an approach which helps the decision maker to identify and choose alternatives based on the values and preferences of the decision makers (Parlos, 2000). MCDM provides an effective framework for comparisons based on the evaluation of multiple conflicting criteria. MCDM is one of the fastest growing areas of operations research, as it has been realized that many concrete problems can be represented by several criteria. It has been described as the most well-known branch of decision making (Jahanshaloo, Zohrehbandian, \& AbbasianNaghneh, 2011; Kasim, Ibrahim, \& Bataineh, 2011). The steps in developing an MCDM application differ in the way in which information on alternatives, performance, criteria and relative significance is elicited, specified and analyzed. However, the MCDM process described below is similar in and applicable to many approaches. The main steps of MCDM are the following:

Step 1. Defining the problem, generating alternatives and establishing criteria: A decision-making problem should start out by clearly defining the problem, discerning the alternatives, identifying the actors, the objectives and any points of conflict, together with the constraints, the degree of uncertainty and the key issues. After this, the problem can be framed to indicate the evaluation criteria.

Step 2. Assigning criteria weights: The criteria weights show the relative importance of the multiple criteria in the problem under consideration and can be determined by techniques such as Analytical Hierarchy Process and Sismos approach.

Step 3. Construction of the evaluation matrix: This is a process in which the essence of the problem is extracted from the complex picture, stated in such a way as to enable the problem to be adequately assessed.

Step 4. Selecting the appropriate method: A multi criteria method must be selected and applied to the problem under consideration in order to rank alternatives. The data and the degree of uncertainty are the key factors for the decision maker when selecting among several multi criteria methods. 
Step 5. Ranking the alternatives: The alternatives are ranked in order of priority and the best ranked alternative is proposed as a solution.

There are two general types of MCDM problem: A problem with a finite number of alternatives and a problem with an infinite number of alternatives (Xu \& Yang, 2001). Some MCDM methods are shown below as quotes from the reference (Parlos, 2000; Kiker, Bridges, Varghese, Seager, \& Linkov, 2005; Saaty, 1980).

Dominance method: Eliminate all dominating alternatives. There could be more than one solution generated by this method. No explicit value judgements are required.

Weighting or scaling methods Comparative: A very popular method in this category is the Simple Additive Weighting method. Value judgments are made about the importance of attributes and weights assigned. This method calculates the overall score of an alternative as the weighted sum of the attribute scores or values. The Analytical Hierarchy Process (AHP) is another popular method in this category.

Mathematical programming models: Value judgments about the importance of an over-all objective are made and weights are developed proportional to the relative value of unit changes in the value function.

Despite many MCDM techniques being available, such as the AHP method (Srisawat \& Payakpate, 2013), which can be enhanced with incremental analysis by a benefit-cost ratio, TOPSIS (technique for order preference by similarity to ideal solution) was chosen by (Hwang \& Yoon, 1981) as the preferred method because of its stability and ease of use with cardinal information. The examples of MCDM use in agriculture are shown as following:

A study by (Becu, Neef, Sangkapitux, \& Schreinemachers, 2008) of agriculture and the natural management area modeled a set of single plots. A water balance model was run for each separate plot as a function with the variables soil texture, soil depth, slope, and the evapotranspiration of the crops grown in the plots. This model was applied to two villages in a watershed in northern Thailand. The application identified several methodological challenges in using participatory computer simulations with local stakeholders.

A separate study by (Tienwong, Dasananda, \& Navanugraha, 2009) evaluated the land suitability for cultivation of two economically important energy crops; sugar cane and cassava, in Kanchanaburi Province, Thailand. To find 
suitable land for this purpose the MCDM integrated the 1976 FAO framework for crop plantations.

\section{ANALYTICAL HIERARCHIES PROCESS}

The Analytical Hierarchies Process (AHP) developed by Thomas Saaty (Saaty \& Vargas, 2001) is one of the best-known and most widely used models for Multiple Attribute Decision Making, because this technique can create a formulation of problems according to hierarchies. It is a powerful decision making methodology for determining priorities among different criteria. Also it can be used with different factors in both quantitative and qualitative data in research. This process uses different factors for decision making, using sensitivity analytisis on all factors and sub factors. It is based on pairwise comparison of alternatives, making it an easy decision making and calculation process (Saaty \& Vargas, 2001; Malczewski, 1999; Saaty, 1990; Saaty, 1994; Saaty, 2000). The AHP steps can be summarized as:

Step 1. The first step is to decompose the decision problem into an hierarchy with a goal at the top, criteria and sub-criteria at levels and sub-levels, and the decision alternatives at the bottom of the hierarchy.

Step 2. The decision matrix, which is based on Saaty's nine point scale, is constructed. The decision maker uses the fundamental 1-9 scale defined by Saaty to assess the priority score (see Table 1 ).

Table 1

Scale of Preference between Two Parameters in AHP (Saaty \& Vargas, 2001)

\begin{tabular}{|c|c|c|}
\hline Scales & Degree of preferences & Explanation \\
\hline 1 & Equally & Two activities contribute equally to the objective. \\
\hline 3 & Moderately & $\begin{array}{l}\text { Experience and judgment slightly to moderately favor } \\
\text { one activity over another. }\end{array}$ \\
\hline 5 & Strongly & $\begin{array}{l}\text { Experience and judgment strongly or essentially favor } \\
\text { one activity over another. }\end{array}$ \\
\hline 7 & Very strongly & $\begin{array}{l}\text { An activity is strongly favored over another and its } \\
\text { dominance has shown in practice. }\end{array}$ \\
\hline 9 & Extremely & $\begin{array}{l}\text { The evidence of favoring one activity over another is of } \\
\text { the highest degree possible of an affirmation. }\end{array}$ \\
\hline $2,4,6,8$ & Intermediate values & $\begin{array}{l}\text { Used to represent compromises between the preferences } \\
\text { in weights } 1,3,5,7 \text { and } 9 \text {. }\end{array}$ \\
\hline Reciprocals & Opposites & Used for inverse comparison. \\
\hline
\end{tabular}


The decision matrix involves the assessments of each alternative in respect to the decision criteria. If the decision making problem consists of $n$ criteria and $m$ alternatives; the decision matrix takes the form:

$$
D=\left[\begin{array}{cccc}
d_{11} & d_{12} & \cdots & d_{1 n} \\
d_{21} & d_{22} & \cdots & d_{2 n} \\
\vdots & \vdots & \vdots & \vdots \\
d_{m 1} & d_{m 2} & \cdots & d_{m n}
\end{array}\right]
$$

The elements $\left\{\mathrm{d}_{i j}\right\}$ signify the rating of the $i^{\text {th }}$ alternative in respect to the $j^{\text {th }}$ criteria.

Step 3. The third step involves the comparison of pairs of the elements of the constructed hierarchy. The aim is to set their relative priorities with respect to each of the elements at the next higher level. The pairwise comparison matrix is based on the Saaty's 1-9 scale, as in

$$
\left[\begin{array}{cccc}
a_{11} & a_{12} & \cdots & a_{1 n} \\
a_{21} & a_{22} & \cdots & a_{2 n} \\
\vdots & \vdots & \cdots & \vdots \\
a_{n 1} & a_{n 2} & \cdots & a_{n n}
\end{array}\right]=\left[\begin{array}{cccc}
\frac{w_{1}}{w_{1}} & \frac{w_{1}}{w_{2}} & \cdots & \frac{w_{1}}{w_{n}} \\
\frac{w_{2}}{w_{1}} & \frac{w_{2}}{w_{2}} & \cdots & \frac{w_{2}}{w_{n}} \\
\vdots & \vdots & \vdots & \vdots \\
\frac{w_{n}}{w_{1}} & \frac{w_{n}}{w_{2}} & \cdots & \frac{w_{n}}{w_{n}}
\end{array}\right]
$$

If $n(n-1) / 2$ comparisons are consistent with the number of criteria $\mathrm{n}$, then the elements $\left\{\mathrm{a}_{i j}\right\}$ will satisfy the following conditions: $a_{i j}=w_{i} / w_{j}=1 / a_{j i}$ and $a_{i i}=1$ with $i=1,2, \ldots m$ and $j, k=1,2, \ldots n$.

In the comparison matrix, $\mathrm{a}_{i j}$ can be interpreted as the degree of preference of the $i^{\text {th }}$ criteria over the $j^{\text {th }}$ criteria. The weight determination of the criteria is more reliable when using pairwise comparisons than when obtaining them directly, because it is easier to make a comparison between two attributes than to make an overall weight assignment.

Step 4. AHP also calculates a consistency ratio $(C R)$, which is a comparison between consistency index $(C I)$ and random consistency index $(R I)$, to reflect the consistency of the decision maker's judgments during the evaluation stage. The consistency index $(\mathrm{Cl})$ in both the decision matrix and in pairwise comparison matrices is calculated with the equation:

$$
C R=\frac{C I}{R I}
$$




$$
C I=\frac{\lambda_{\max }-N}{N-1}
$$

The closer the inconsistency index is to zero, the greater the consistency. The consistency of the assessments is ensured if the equality $\mathrm{a}_{i j} \cdot \mathrm{a}_{j k}=\mathrm{a}_{i k}$ holds for all criteria. The relevant index should be lower than 0.10 to accept the AHP results as reliable. If this is not the case, the decision-maker should revert to Step 2 and then Step 3 and redo the assessments and comparisons. An acceptable consistency ratio helps to ensure decision-maker reliability in determining the priorities of a set of criteria.

Table 2

Average Random Consistency Index (RI) Based on Matrix Size (Saaty \& Vargas, 2001)

\begin{tabular}{ccc}
\hline S. No. & Size of Matrix (n) & Random Consistency Index (RI) \\
\hline 1 & 1 & 0 \\
2 & 2 & 0 \\
3 & 3 & 0.52 \\
4 & 4 & 0.89 \\
5 & 5 & 1.11 \\
6 & 6 & 1.25 \\
7 & 7 & 1.35 \\
8 & 8 & 1.40 \\
9 & 9 & 1.45 \\
10 & 10 & 1.49 \\
\hline
\end{tabular}

Step 5. Before the calculation of the vector of priorities can be done, the comparison matrix must be normalized. Consequently, each column must be divided by the sum of the entries in the corresponding column. By this means, a normalized matrix is obtained in which the sum of the elements of each column vector is 1 .

Step 6. This is the most comprehensive step, in which the eigenvalues of the normalized comparison matrix are calculated to give the relative weights of the criteria. The relative weights obtained in the third step should be verified.

$$
A \times W=\lambda_{\max } \times W
$$


where A represents the pairwise comparison matrix and $\lambda_{\max }$ the highest eigenvalue. If there are elements at the higher levels of the hierarchy, the obtained weight vector is multiplied by the weight coefficients of the elements at the higher levels, until the top of the hierarchy is reached. The alternative with the highest weight coefficient value should be taken as the best alternative. The final result consists of the derived factor weights and class weights, and a calculated consistency ratio $(C R)$, as seen in Table 3 and Table 4.

Table 3

The Result of AHP Calculation of Physical Weights for Evaluation the Suitable Plant in Rubber Areas

\begin{tabular}{ll}
\hline \multicolumn{1}{c}{ Values } & Weight \\
\hline Annual Rainfall & 0.3288 \\
Soil Fertility & 0.2280 \\
Soil Drainage & 0.1721 \\
Soil Texture & 0.1209 \\
Soil Depth & 0.1006 \\
Slope & 0.0496 \\
\hline
\end{tabular}

Max Eigen Values $\left(\lambda_{\max }\right)=6.4542$

Consistency Index $(C I)=0.0908$

Consistency Ratio $(C R=C I / R I)=0.0727$

Table 4

The Result of AHP Calculation of Economic Weights

\begin{tabular}{ll}
\hline \multicolumn{1}{c}{ Values } & Weight \\
\hline Selling Rate per Kilogram & 0.7500 \\
Asset (Baht per unit of area) & 0.2500 \\
\hline
\end{tabular}

Max Eigen Values $\left(\lambda_{\text {max }}\right)=2.0000$

Consistency Index $(C I)=0.0000$

Consistency Ratio $(C R=C I / R I)=0.0000$

In AHP, the consistency used to build a matrix is checked by a consistency ratio, which depends on the number of parameters. For a $5 \times 5$ matrix, the $C R$ must be less than 0.1 to accept the computed weights. The $C R$ is a ratio between the matrix's consistency index and random consistency index, and in generally ranges from 0 to 1 . The random consistency index is the average consistency index obtained by generating large numbers of random matrices. A $C R$ close to 0 indicates a high probability that the weights were generated 
randomly (Srisawat \& Payakpate, 2013; Malczewski, 1999). The models with a $C R$ greater than 0.1 are automatically rejected, while a $C R$ less than 0.1 is often acceptable. With the AHP method, the values of the spatial factor weights are defined. Using a weighted linear sum procedure (Saaty \& Vargas, 2001), the acquired weights are used to calculate the landslide susceptibility.

\section{TECHNIQUE FOR ORDER PREFERENCE BY SIMILARITY TO IDEAL SOLUTION}

The Technique for Order Preference by Similarity to Ideal Solution (TOPSIS) method was first proposed in 1981 by Hwang and Yoon (Hwang \& Yoon, 1981). This method is based on choosing the best alternative having the shortest distance to the ideal solution and the farthest distance from the negative-ideal solution. The ideal solution is the solution that maximizes the benefit and also minimizes the total cost. Alternatively, the negative-ideal solution is the solution that minimizes the benefit and also maximizes the total cost.

For the first step of this methodology, the decision matrix, which represents the performance values of each alternative with respect to each criterion, is computed. Then, these performance values are multiplied by the criteria weights calculated with AHP. The step of defining the ideal solution consists of taking the best values of alternatives and similarly, the negative-ideal solution is obtained by taking the worst values of alternatives. Subsequently, the alternatives are ranked with respect to their relative closeness to the ideal solution. The TOPSIS method can be summarized as follows:

Step 1. The first step of the procedure involves the calculation of the normalized decision matrix. The normalized value $\left\{\mathrm{r}_{i j}\right\}$ is calculated as

$$
r_{i j}=\frac{x_{i j}}{\sqrt{\sum_{i=1}^{m} x_{i j}^{2}}}, i=1,2, \ldots, m ; j=1,2, \ldots, n
$$

Step 2. In the next step, the weighted normalized decision matrix $\mathrm{V}=\left(\mathrm{v}_{i j}\right)_{m \times n}$ is calculated. The weighted normalized value $\mathrm{v}_{i j}$ is calculated as

$$
v_{i j}=w_{j} r_{i j}, i=1,2, \ldots, m ; j=1,2, \ldots, n
$$

where $\mathrm{w}_{j}$ is the weight of the $j^{\text {th }}$ criterion.

Step 3. Determine the positive ideal and negative ideal solutions by: 


$$
A^{*}=\left\{v_{1}^{*}, v_{2}^{*} \ldots, v_{n}^{*}\right\}=\left\{\left(\max _{i} v_{i j}\left|j \in I^{\prime}, \min _{i} v_{i j}\right| j \in I^{\prime \prime}\right)\right\}
$$

and

$$
A^{-}=\left\{v_{1}^{-}, v_{2} \ldots, v_{n}^{-}\right\}=\left\{\left(\min _{i} v_{i j}\left|j \in I^{\prime}, \max _{i} v_{i j}\right| j \in I^{\prime \prime}\right)\right\}
$$

where $\mathrm{I}^{\prime}$ is associated with the benefit criteria, and $\mathrm{I}^{\prime \prime}$ is associated with the cost criteria.

Step 4. The separation measures are calculated using the $\mathrm{n}$ dimensional Euclidean distance. The separation of each alternative from the ideal solution is given as

$$
D_{i}^{*}=\sqrt{\sum_{j=1}^{n}\left(v_{i j}-v_{i}^{*}\right)^{2}}, i=1,2, \ldots, m
$$

and

$$
D_{i}^{-}=\sqrt{\sum_{j=1}^{n}\left(v_{i j}-v_{i}^{-}\right)^{2}}, i=1,2, \ldots, m
$$

Step 5. This step consists of the calculation of the relative closeness of the alternatives to the ideal solution. The relative closeness of the alternative a with respect to $\mathrm{A}^{*}$ is defined as

$$
C_{i}=\frac{D_{i}^{-}}{D_{i}^{*}+D_{i}^{-}}, i=1,2, \ldots, m
$$

Step 6. The alternatives are now ranked according to their relative closeness to the ideal solution. The bigger the $\mathrm{C}_{i}$, the better the alternative $\mathrm{A}_{i}$. The best alternative is the one with the greatest relative closeness to the ideal solution.

\section{SIMPLE ADDITIVE WEIGHTING}

The Simple Additive Weighting (SAW) method is also referred to as a weighted linear combination or scoring method or weighted sum method. It is a simple method to apply and is most often used with multi-attribute decision technique. It is based on the weighted average developed by Fishburn (1967). An evaluation score is calculated for each alternative by multiplying the scaled value given to the alternative of that attribute with the weights of relative 
importance directly assigned by the decision maker, followed by summing of the products for all criteria. All the elements of the decision table are normalized, and then SAW can be used for any type and any number of attributes. The overall or composite score $\mathrm{P}_{i}$ of the alternative $\mathrm{A}_{i}$ is determined as in

$$
P_{i}=\sum_{j=1}^{n} w_{j}\left(y_{i}\right)_{\text {normal }}
$$

where $\left(\mathrm{y}_{i j}\right)_{\text {normal }}$ represents the normalized value of $\mathrm{y}_{i j}$. The alternative with the highest composite score, $\mathrm{P}_{i}$ is considered as the best alternative.

\section{A FRAMEWORK FOR INTERCROP SELECTION IN RUBBER PLANTATION}

For the purposes of this study, Figure 1 shows the decision hierarchy for land suitability of a rubber plantation to find the best intercrop plantings for rubber trees, such as pineapples, sweet corn, maize, cassava, papaya, bananas or shallots cultivation.

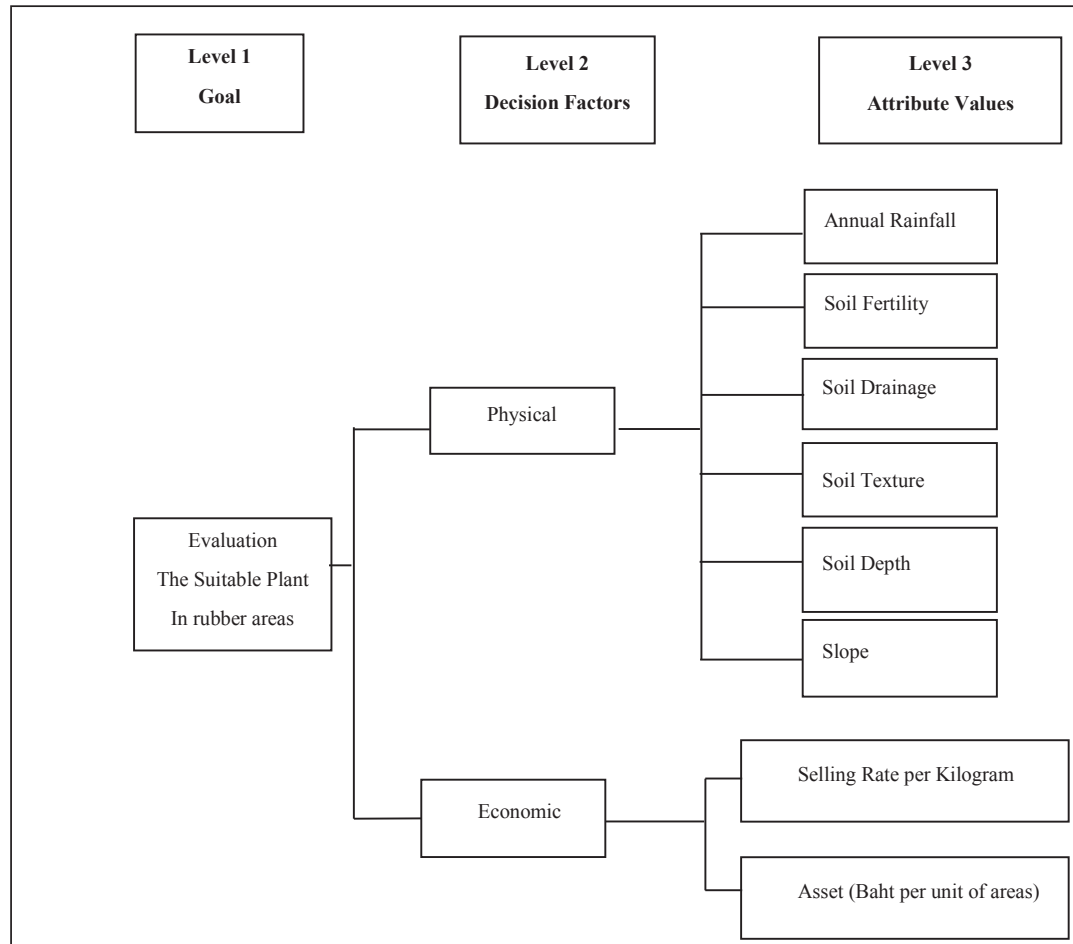

Figure 1. Decision hierarchy for land suitability. 
Three methods, AHP, SAW and TOPSIS, were applied to both physical criteria and economic criteria. The result of AHP is shown in Table 3, The $C R$ of Physical weight attributes such as Annual Rainfall is 0.3288 , Soil Fertility is 0.2280 , Soil Drainage is 0.1721 , Soil Texture is 0.1209 , Soil Depth is 0.1006 , and Slope is 0.0496 . Table 4 is the $C R$ of Economic weight attributes of AHP method such as Selling Rate per Kilogram is 0.7500 and Asset is 0.2500 . Then Table 5 and Table 6 are shown the result of TOPSIS and SAW that are the same, for example Annual Rainfall is 0.0856 , Soil Fertility is 0.1023 , Soil Drainage is 0.1023 , Soil Texture is 0.1044 , Soil Depth is 0.0898 , and Slope is 0.1044 .

Table 5

The Result of TOPSIS Calculation of Physical Weight for Evaluation the Suitable Plant in Rubber Areas

\begin{tabular}{ll}
\hline \multicolumn{1}{c}{ Values } & Weight \\
\hline Annual Rainfall & 0.0856 \\
Soil Fertility & 0.1023 \\
Soil Drainage & 0.1023 \\
Soil Texture & 0.1044 \\
Soil Depth & 0.0898 \\
Slope & 0.1044 \\
\hline
\end{tabular}

Table 6

The Result of SAW Calculation of Physical Weight for Evaluation the Suitable Plant in Rubber Areas

\begin{tabular}{|c|c|}
\hline Values & Weight \\
\hline Annual Rainfall & 0.0856 \\
\hline Soil Fertility & 0.1023 \\
\hline Soil Drainage & 0.1023 \\
\hline Soil Texture & 0.1044 \\
\hline Soil Depth & 0.0898 \\
\hline Slope & 0.1044 \\
\hline
\end{tabular}

The finals of the result are shown as Table 7 and Table 8 that the same result of TOPSIS and SAW for instance Selling Rate per Kilogram is 0.5521 and Asset is 0.4479 . 
Table 7

The Result of TOPSIS Calculation of Economic Weights

\begin{tabular}{ll}
\hline \multicolumn{1}{c}{ Values } & Weight \\
\hline Selling Rate per Kilogram & 0.5521 \\
Asset (Baht per unit of area) & 0.4479 \\
\hline
\end{tabular}

Table 8

The Result of AHP Calculation of Economic Weights

\begin{tabular}{ll}
\hline \multicolumn{1}{c}{ Values } & Weight \\
\hline Selling Rate per Kilogram & 0.5521 \\
Asset (Baht per unit of area) & 0.4479 \\
\hline
\end{tabular}

\section{COMPARISON OF RESULTS FROM AHP, TOPSIS AND SAW}

AHP is a mathematical calculation with fixed rules, and its reliability can be accepted generally in any decision making process. SAW and TOPSIS, on the other hand, allow the decision maker to do the calculations according to their own rules, for the particular decision requirements being considered. SAW and TOPSIS therefore do not hold for general belief and is suitable only in small groups and cannot be used widely.

Only AHP can calculate the reliability and provide consistency in judgment. TOPSIS and SAW cannot provide controlled consistency because they do not have comparative indexes as indicators.

The AHP method uses a hierarchical structure by pairwise comparison. It becomes complicated for a problem structure with a number of alternatives or criteria as the number of comparisons increases. TOPSIS and SAW can solve the selection problem. These processes provide numerous alternatives and criteria because of the simple mathematical calculations involved.

AHP and SAW both focus on a model from which a vector of global scores is obtained by conflicting alternatives. On the other hand, TOPSIS is classified under compromising models, with the concept that no ideal solution exists, but a solution with optimal values of all attributes is all selected. 
The principle calculation of each MCDM method has its unique solution algorithm. AHP uses the hierarchy principle and pairwise comparison matrices to select the obtained alternative rankings, whereas SAW applies the principle of weighted average of assigning a scalar value to each alternative, while TOPSIS calculates the shortest distance of an alternative from the positive ideal solution and the longest distance from the negative-ideal solution.

In this study, the problem structure includes the number of criteria used and the number of alternatives selected in a decision-making problem. AHP uses a hierarchical structure by pairwise comparison for solving the selection problem. AHP shows a controlled consistency, unlike SAW and TOPSIS. In terms of the final result, AHP is suitable for small-scale data and reasonably simple problem, such as is being used for this research.

Table 9

The Result of AHP Calculation of Economic Weights

\begin{tabular}{ll}
\hline \multicolumn{1}{c}{ Values } & Weight \\
\hline Selling Rate per Kilogram & 0.5521 \\
Asset (Baht per unit of area) & 0.4479 \\
\hline
\end{tabular}

Table 10

Compare the Result of Various MCDM Approaches Calculation of Physical Weights

\begin{tabular}{lccc}
\hline \multirow{1}{*}{ Values } & \multicolumn{3}{c}{ Plant Selection Index } \\
\cline { 2 - 4 } & AHP & TOPSIS & SAW \\
\hline 1. Annual Rainfall & 0.3288 & 0.0856 & 0.0856 \\
2. Soil Fertility & 0.2280 & 0.1023 & 0.1023 \\
3. Soil Drainage & 0.1721 & 0.1023 & 0.1023 \\
4. Soil Texture & 0.1209 & 0.1044 & 0.1044 \\
5. Soil Depth & 0.1006 & 0.0898 & 0.0898 \\
6. Slope & 0.0496 & 0.1044 & 0.1044 \\
RANK & $1-2-3-4-5-6$ & $4,6-2,3-5-1$ & $4,6-2,3-5-1$ \\
\hline
\end{tabular}




\section{Table 11}

Compare the Result of Various MCDM Approaches Calculation of Economic Weights

\begin{tabular}{lccc}
\hline \multirow{2}{*}{\multicolumn{1}{c}{ Values }} & \multicolumn{3}{c}{ Plant Selection Index } \\
\cline { 2 - 4 } & AHP & TOPSIS & SAW \\
\hline 1. Selling Rate per Kilogram & 0.7500 & 0.5521 & 0.5521 \\
2. Asset (Baht per unit of area) & 0.2500 & 0.4479 & 0.4479 \\
RANK & 1,2 & 1,2 & 1,2 \\
\hline
\end{tabular}

\section{CONCLUSION}

This paper presented a comparison of three MCDM methods used in maintenance decision making. According to the comparison section above, AHP is the most appropriate method for intercrop selection in rubber plantation. In addition, the stability of AHP allows decision maker applied these result to other area. For example, Physical Weights in Table 10 were calculated based on spatial data of Phitsanulok (a province of Thailand) in 2012. Decision maker can apply these weights to other provinces. While, the other two methods, decision maker needs to re-calculation. For future work, we plan to develop a decision support system for rubber plantation selection intercrop with MCDM. Therefore, the integrated MCDM with web-based GIS provides a list of the appropriate intercrop for particular rubber field.

\section{REFERENCES}

Becu, N., Neef, A., Sangkapitux, C., \& Schreinemachers, P. (2008). Participatory computer simulation to support collective decisionmaking: Potential and limits of stakeholder involvement. Land Use Policy, 25(4), 498-509.

Corre-Hellou, G., Fustec, J., \& Crozat, Y. (2006). Interspecific competition for soil $\mathrm{N}$ and its interactions with $\mathrm{N} 2$ fixation, leaf expansion and crop growth in pea-barley intercrops. Plant Soil, 282, 195-208.

Fishburn, P. C. (1967). Additive utilities with incomplete product set: applications to priorities and assignments. Operations Research Society of America (ORSA), 15(3), 357-542. 
Hamzei, J., \& Seyyedi, M. (2016). Energy use and input-output costs for sunflower production in sole. Soil \& Tillage Research, 73-82.

Hauggaard-Nielsen, H., Ambus, P., \& Jensen, E. S. (2001a). Temporal and spatial distri- bution of roots and competition for nitrogen in pea-barley intercrops - a field study employing P-32 technique. Plant Soil, 236, 63-74.

Hauggaard-Nielsen, H., Ambus, P., \& Jensen, E. S. (2001b). Interspecific competition $\mathrm{N}$ use and interference with weeds in pea-barley intercropping. Field Crops Res, 70, 101-109.

Hu, F., Gan, Y., Cui, H., Zhao, C., Feng, F., Yin, W., \& Chai, Q. (2016). Intercropping maize and wheat with conservation agricultureprinciples improves water harvesting and reduces carbon emissionsin dry areas. European Journal of Agronomy, 9-17.

Hwang, C. L., \& Yoon, K. (1981). Multiple attribute decision making methods and applications. Berlin: Springer-Verlag.

Jahanshaloo, G. R., Zohrehbandian, M., \& Abbasian-Naghneh, S. (2011). using interactive multiobjective methods to solve multiple attribute decision making problems. Australian Journal of Basic and Applied Sciences, 5(9), 298-308.

Kasim, M. M., Ibrahim, H., \& Bataineh, M. S. (2011). Multi-crireria decision making methods for determining computer preference index. Journal of ICT, 10, 137-148. Retrieved from http://www.jict.uum.edu.my/images/ pdf2/vol10/jict108.pdf

Kiker, A. G., Bridges, S. T., Varghese, A., Seager, T. P., \& Linkov, I. (2005, April). Application of multicriteria decision analysis in environmental decision making. Integrated Environmental Assessment and Management, l(2), 95-108.

Malczewski, J. (1999). Gis and multi-criteria decision analysis. NY: John Wiley and Sons.

Miao, Q., Rosa, R. D., Shi, H., Paredes, P., Zhu, Li., Dai, J., Goncalves, J. M., \& Pereira, L. S. (2016). Modeling water use, transpiration and soil evaporation of springwheat-maize and spring wheat-sunflower relay intercropping usingthe dual crop coefficient approach. Agricultural Water Management, 211-229. 
Ofori, F., \& Stern, W. R. (1978). Cerreal-legume intercropping systems. Adv. Agron, 41, 41-90.

Parlos, M. P. (2000). Multi-criteria decision making methods: A comparative study. Dordecht: Kluwer academic publishers.

Saaty, T. L. (1980). The analytical hierarchy process. NY: McGraw Hill.

Saaty, T. L. (1990). The analytic hierarchy process: planning, priority setting, resource allocation. Pittsburgh: RWS Publications.

Saaty, T. L. (1994). Fundamentals of decision making with the analytic hierarchy process. Pittsburgh. RWS Publications.

Saaty, T. L. (2000). Fundamentals of decision making and priority theory. Pittsburgh: RWS Publications.

Saaty, T. L., \& Vargas, L. G. (2001). Models, methods, concepts, and applications of the analytic hierarchy process. Boston: Kluwer Academic.

Snaydon, R. W., \& Satorre, E. H. (1989). Bivariate diagrams for plant competition data-modifications and interpretation. J. Appl. Ecol, 26, 1043-1057.

Srisawat, C., \& Payakpate, J. (2013, July 14-17). Multi Criteria decision making - developer view: Applications in Thailand. International Conference on Machine Learning and Cybernetics (ICMLC), 04, 1661-1664.

Stewart, T. J. (1992). A critical survey on the status of multiple ceiteria decision making theory and practice. OMEGA International Journal of Management Science, 20(5-6), 569-586.

Tienwong, K., Dasananda, S., \& Navanugraha, C. (2009). Integration of land evaluation and the analytical hierarchical process method for energy crops in Kanchanaburi, Thailand. Science Asia, 35(2), 170-177.

Willey, R. (1979). Intercropping-its importance and research needs. Part 1. Competition and yield advantages. Field Crops Abstar, 32, 1-10. 
Xu, D. L., \& Yang, J. B. (2001, May). Introduction to multi-criteria decision making and the evidential reasoning approach. Manchester School of Management, University of Manchester Institute and Technology. 